\title{
In vitro production of zygote from slaughterhouse driven buffalo oocyte
}

\author{
G.K. Deb ${ }^{1}$, M.F.H Miraz ${ }^{1 *}$, S.M.J. Hossain ${ }^{1}$, M.F. Afroz ${ }^{1}$, M.A. Kabir ${ }^{1}$ and S. Akhter ${ }^{2}$ \\ ${ }^{1}$ Biotechnology Division, Bangladesh Livestock Research Institute, Savar, Dhaka 1341 \\ ${ }^{2}$ Breed up gradation through progeny test project (3rd phase), Department of Livestock Services
}

\begin{abstract}
Buffalo is a highly potential animal species in terms of milk and meat production but traditionally they are regarded as poor breeder. In vitro embryos production technology has been introduced in many countries to improve reproductive efficiency of buffalo. Considering the above fact, the present study was undertaken aiming to produce in vitro buffalo embryo in the laboratory. Ovaries of slaughtered buffaloes were collected from abattoir and transported to the laboratory within 4 to $5 \mathrm{hr}$ of slaughter. Cumulusoocyte-complexes (COCs) possessing an even cytoplasm and covered with minimum 3 layers of compact cumulus cells was selected for in vitro maturation (IVM) for $24 \mathrm{hr}\left(5 \% \mathrm{CO}_{2}\right.$ in air at $38.5^{\circ} \mathrm{C}$ with maximum humidity). After IVM, the presumptive matured COCs were co-cultured with capacitated fresh spermatozoa for $18 \mathrm{hr}$ After IVF, the presumptive zygote were denuded, washed and transferred in to in vitro culture medium (IVC 1) for 3 days. After three days cleavage were recorded and 4 cell embryos were transferred in to in vitro culture media II for next 2 days. The development of embryos was evaluated on day 6 . A total of 227 buffalo ovaries were collected from the slaughterhouse and categorized into 2 groups based on presence $(n=83)$ or absence $(n=144)$ of corpus luteum $(C L)$. A total of 1464 follicles were counted on the ovarian surface, 1066 being from CL absent and 398 from CL-containing ovaries. A significantly higher $(\mathrm{P}<0.01)$ number of follicles, aspirated follicles, normal COCs and total COCs $(7.4 \pm$ $0.21,5 \pm 0.00,1.98 \pm 0.77$ and $2.98 \pm 0.16$ respectively) were observed in CL-absent ovaries than those aspirated from CL-containing ovaries ( $4.80 \pm 0.17,3.92 \pm 0.95,0.88 \pm 0.60$ and $1.88 \pm 0.16$ respectively). Total 358 normal COCs were set for in vitro maturation and underwent for IVF and IVC. Results showed that cleavage rates were $56.42 \%$. Among the cleaved embryos, 137 were at 2-cell stage and 65 were at 4-cell stage. Therefore, development rate to 2 cell and 4-cell stage was $38.27 \%$ and $18.15 \%$ respectively. No embryo developed beyond 4-cell stage. This result indicates that follicle and oocyte numbers and oocyte quality are associated with CL of ovaries and current culture system support in vitro embryo production upto 4-cell stage. The in vitro culture condition may be improved for increasing efficiency of embryo production.
\end{abstract}

(Key words: Buffalo, oocyte, in vitro maturation, Cumulus oocyte complexes, cleavage)

\section{Introduction}

Buffalo is an economically important livestock species in Bangladesh. The total buffalo population is about 1.464 million in Bangladesh (DLS, 2015), with about $40 \%$ of the population in the coastal regions (Faruque et al., 1990). Buffaloes are reported to have low reproductive performance with several inherent reproductive problems, such as silent estrus, seasonal anestrous, delayed puberty, delayed first calving, late post-partum conception and a long calving interval (Nandi et al., 2002). In order to improve reproductive efficiency of buffalo, assisted reproductive technologies such as artificial insemination (AI), multiple ovulation and embryo transfer (MOET) and in vitro production of embryos have been introduced (Nandi et al., 2002).

*Corresponding author: miraz.blri@gmail.comm

Bang. J. Livs. Res. Special Vol. 21-25, 2018: P. 127-132, ISSN 1022-3851 
In vitro embryo production (IVEP) technology is used for rapid multiplication and distribution of high yielding buffaloes in many developed and developing countries. Application of these technologies in assisted reproduction of buffalo is necessary to rescue the precious germplasm due to wastage by indiscriminate slaughter of this animal. IVEP by means of IVF has drawn the interest of innumerable researchers as it can salvage the genetic potential from infertile female and can yield large number of embryos from the ovaries of slaughtered females.

Substantial improvement to the in vitro embryo production systems available for buffalos is required, which still remain in sub-optimal levels, compared to those applied in bovines. Therefore, considerable basic developmental work still has to be undertaken in order to standardize IVEP techniques for buffalos.

Research on buffalo IVEP is remained at very preliminary stages including evaluation of follicular statistics, COCs recovery rate, grading of COCs and in vitro maturation of COCs (Khandoker et al., 2011 and 2012). So, adoption of culture system for development of embryos up to blastocyst stage is essential. From this point of view, the present study was undertaken aiming to produce in vitro buffalo embryo in the laboratory.

\section{Materials and Methods}

\section{Collection, grading and aspiration of oocytes}

Ovaries of slaughtered buffaloes was collected from abattoir located at Kaptan bazar, City Corporation Slaughterhouse, Gulistan, Dhaka in physiological saline $(0.9 \%$ sodium chloride supplemented with
$100 \mathrm{IU} / \mathrm{mL}$ penicillin and $0.1 \mathrm{~g} / \mathrm{mL}$ streptomycin sulfate) at ambient temperature and transported to the laboratory within 4 to $5 \mathrm{hr}$ of slaughter. In the laboratory, extraneous tissue was removed and ovaries were washed with phosphate buffer saline (PBS). The collected ovaries were divided into two groups according to presence and absence of $\mathrm{CL}$. The cumulus-oocyte-complexes (COCs) were aspirated using a $10-\mathrm{mL}$ disposable syringe attached with a $21 \mathrm{G}$ needle. The collected cumulus-oocyte-complexes (COCs) were graded as normal and abnormal grade for in vitro maturation (IVM) based on their size, diameter and quality of cumulus cell.

\section{In vitro maturation (IVM)}

The aspirated material were poured onto a 100-mm petridish containing TL-HEPES (114-mM sodium chloride, 3.2-mM potassium chloride, 2-mM sodium bicarbonate, 0.34-mM sodium biphosphate, $10-\mathrm{mM}$ sodium lactate, 0.5-mM magnesium chloride, 2.0-mM calcium chloride, $10-\mathrm{mM}$ hepes, $1 \mu \mathrm{L} / \mathrm{mL}$ phenol red, $100 \mathrm{IU} / \mathrm{mL}$ penicillin, and 0.1 $\mathrm{mg} / \mathrm{mL}$ streptomycin) solution and the cumulus-oocyte-complexes (COCs) were searched under a microscope at low magnification $(4 \mathrm{x})$. The 'normal' cumulusoocyte-complexes (COC) possessing an even cytoplasm and covered with minimum 3 layers of compact cumulus cells were selected for in vitro maturation (Stojkovic et al., 2001). The selected COCs (50 to 70 per well) were washed 2-3 times in TL-HEPES and 2-3 times in IVM medium (TCM199+ $10 \%$ FBS, $1 \mu \mathrm{g} / \mathrm{mL} \beta$-estradiol, $10 \mu \mathrm{g} / \mathrm{mL}$ FSH, 0.6-mM cystein, and $0.2-\mathrm{mM}$ sodium pyruvate) before placing them into a well of 4-well dish containing 500 to $700 \mu \mathrm{L}$ IVM medium for 22 to $24 \mathrm{hr}$. 


\section{In vitro fertilization (IVF)}

The matured COCs were fertilized in vitro by fresh semen collected from buffalo bulls of BLRI buffalo farm using artificial vagina method. $10 \mu \mathrm{L}$ semen was placed in a $15-\mathrm{mL}$ conical tube containing $10 \mathrm{~mL}$ D-PBS and pelleted by centrifugation at $750 \times \mathrm{g}$ for $5 \mathrm{~min}$. The supernatant was removed carefully and $10 \mathrm{~mL}$ D-PBS was added in the tube. The sperm was washed for 2-3 times accordingly. Then spermatozoa was capacitated through incubation with $500 \mu \mathrm{L}$ IVF medium (Tyrode's lactate solution supplemented with $6 \mathrm{mg} / \mathrm{mL}$ BSA, $22 \mu \mathrm{g} / \mathrm{mL}$ sodium pyruvate, $100 \mathrm{IU} / \mathrm{mL}$ penicillin, and $0.1 \mathrm{mg} / \mathrm{mL}$ streptomycin) containing heparin sodium salt $(20 \mu \mathrm{g} / \mathrm{mL})$ for $15 \mathrm{~min}$. After capacitation, the spermatozoa diluted at approximately $1 \times 106$ spermatozoa $/ \mathrm{mL}$ with IVF medium. The matured COC were co-cultured with capacitated spermatozoa for 18 to $20 \mathrm{~h}$ through placing them into a well of 4-well dish $(500$ to $700 \mu \mathrm{L})$.

\section{In vitro culture (IVC)}

The cumulus cells was removed by gentle pipetting into TL-HEPES and the denuded presumed zygotes were placed in the well of a four-well dish containing 500-700 $\mu \mathrm{L}$ modified CR1-aa medium (Rosenkrans et al., 1993) supplemented with Na-pyruvate, glutamine, penicillin/streptomycin, BSA and glutathione for 3 days (IVC-I). These were cultured until day 8 of embryonic development in a medium of the same composition, except that the BSA was replaced with FBS (IVC II). The incubation conditions during IVM, IVF and IVC was 5\% $\mathrm{CO}_{2}$ in air at $38.5^{\circ} \mathrm{C}$ with maximum humidity.

\section{Statistical analysis}

All values relating to follicut or statistics were expressed as Mean \pm SE. The statistical analysis were done using SPSS IMB 20.0 version software programme.

\section{Results and Discussion}

\section{Quantitative evaluation of ovarian follicles}

A total of 227 buffalo ovaries were collected from the slaughterhouse and categorized into 2 groups based on presence $(\mathrm{n}=83)$ or absence $(\mathrm{n}=144)$ of corpus luteum (CL). A total of 1464 follicles were counted on the

Table 1. Effects of CL on follicular statistics and COCs collection in buffalo ovaries

\begin{tabular}{|c|c|c|c|c|c|}
\hline \multirow[t]{2}{*}{$\begin{array}{l}\text { Ovarian } \\
\text { type }\end{array}$} & \multirow{2}{*}{$\begin{array}{l}\text { Follicles per } \\
\text { ovary } \\
(\text { Mean } \pm \text { SE) }\end{array}$} & \multirow{2}{*}{$\begin{array}{c}\text { Aspirated follicles } \\
\text { per ovary } \\
(\text { Mean } \pm \text { SE) }\end{array}$} & \multicolumn{2}{|c|}{$\begin{array}{l}\text { Collected COCs per ovary } \\
(\text { Mean } \pm \text { SE) }\end{array}$} & \multirow{2}{*}{$\begin{array}{c}\text { Total COCs per } \\
\text { ovary } \\
(\text { Mean } \pm \text { SE) }\end{array}$} \\
\hline & & & Normal & Abnormal & \\
\hline $\begin{array}{l}\text { CL absent } \\
\text { ovary (144) }\end{array}$ & $\begin{array}{l}7.4^{\mathrm{a}} \pm 0.21 \\
\quad(1066)\end{array}$ & $\begin{array}{l}5.00^{\mathrm{a}} \pm 0.00 \\
\quad(720)\end{array}$ & $\begin{array}{l}1.98^{\mathrm{a}} \pm 0.77 \\
(285)\end{array}$ & $\begin{array}{l}1.1 \pm 0.53 \\
(144)\end{array}$ & $\begin{array}{l}2.98^{\mathrm{a}} \pm 0.16 \\
\quad(429)\end{array}$ \\
\hline $\begin{array}{l}\text { CL present } \\
\text { ovary }(83)\end{array}$ & $\begin{array}{c}4.80^{\mathrm{b}} \pm 0.17 \\
\quad(398)\end{array}$ & $\begin{array}{l}3.92^{\mathrm{b}} \pm 0.95 \\
\quad(325)\end{array}$ & $\begin{array}{l}0.88^{b} \pm 0.60 \\
\quad(73)\end{array}$ & $\begin{array}{l}1.1 \pm 0.5 \\
(83)\end{array}$ & $\begin{array}{l}1.88^{\mathrm{b}} \pm 0.16 \\
\quad(156)\end{array}$ \\
\hline Total (227) & $\begin{array}{c}6.45 \pm 0.21(146 \\
4)\end{array}$ & $\begin{array}{l}4.60 \pm 0.9 \\
(1045)\end{array}$ & $\begin{array}{l}1.58 \pm 0.10 \\
\quad(358)\end{array}$ & $\begin{array}{l}1.1 \pm 0.06 \\
(227)\end{array}$ & $\begin{array}{l}2.58 \pm 0.13 \\
(585)\end{array}$ \\
\hline
\end{tabular}

Means bearing different superscripts $(a, b)$ differ significantly $(p<0.05)$ 
ovarian surface, 1066 being from CL absent and 398 from CL-containing ovaries. Not all these follicles were suitable for aspiration. The total number of aspirated follicles was 1045, from which 720 were aspirated from CL-absent ovaries, while 325 were aspirated from CL containing ovaries. A significantly higher $(\mathrm{P}<0.01)$ number of follicles was observed in CL-absent ovaries than in CL-containing ovaries (Table 1). Consequently, the number of aspirated follicles from CL-absent ovaries was significantly higher $(\mathrm{P}<0.01)$ than those aspirated from $\mathrm{CL}-$ containing ovaries (Table 1).

The higher number of follicles found in without CL ovaries than those of with CL ovaries fits with the endocrinological explanation. The presence of corpus luteum in cyclic ovary cause a higher level of progesterone hormone production in which giving a negative response to anterior pituitary gland for the restriction of gonadotrophin secretion and leads to follicular degeneration and inhibition of the development of large follicles (Webb et al., 1999). In noncyclic female, the absence of corpus luteum cause no negative effect of progesterone on anterior pituitary and thus estrogen-progesterone levels remains balanced which allows the growth of follicles. Ginther et al. (1996) stated that ovaries without CL, the decrease in progesterone leads to increase in $\mathrm{GnRH}$ which stimulates the release of follicle stimulating hormone (FSH) and this hormone causes the rapid growth of ovarian follicles.

The results strongly supported by the previous finding of Khandoker et al. (2011) who reported that significantly higher number of follicles were found in ovaries without CL (6.78 \pm 0.18$)$ than in CL containing ovaries (4.09 \pm 0.26$)$. Similar findings also found by Asad (2015), who reported that higher number of follicles aspirated per ovary in without CL group $(2.92 \pm 0.08)$ than those of the with CL group (2.52 \pm 0.11$)$ in goat.

\section{Quantitative and qualitative evaluation of COCs}

Both the number and quality of the COCs are important to initiate the embryo culture experiment. Significantly higher $(\mathrm{P}<0.01)$ number of normal COCs was found in CL-absent ovaries compared to CL-containing ovaries. The mean retrieved COCs per ovary was higher in CL-absent ovaries than in CL-present ovaries (2.98 vs. $1.88 \mathrm{COCs})$. The cause for the low number of oocytes in ovaries containing a CL is likely because of the restricted follicular development, as lutein cells occupy a great portion of the ovary; furthermore, CL may inhibit the follicular growth and foster their atresia.

Nandi et al. (2000) stated that when ovaries had a corpus luteum, the oocyte recovery rate decreases. This is because there will be restriction of follicular development as lutein cells occupy most of the ovary (Kumar et al., 2004). Hafez (1993) mentioned that in the presence of CL in ovary, the growth of follicle is inhibited while atresia is increased. These statements can be the physiological explanation for lower number of COCs in the with $\mathrm{CL}$ ovaries compared to without $\mathrm{CL}$ ovaries. Similarly, the higher number of normal COCs in CL absent group ovaries may be due to the hormonal effect of CL. When CL is absent in the ovary, progesterone which has role in follicular degeneration could not be produced (Hafez, 1993). Thus, folliculogenesis can occur successfully and 
further there is more chance to produce high quality of COCs. Therefore, the types of ovary at the time of COCs collection have affected the quantity and quality of COCs recovered as well as usable oocytes in animals for use in IVEP program.

\section{In vitro embryo production}

Collected total 358 normal COCs were allowed for in vitro maturation $(5 \% \mathrm{CO} 2$ in air at $38.5^{\circ} \mathrm{C}$ with maximum humidity) in which 285 oocytes showed cumulus expansion at the rate of $79.61 \%$. All the expanded $\mathrm{COCs}$ were allowed for in vitro current study than standard culture system (Dey et al., 2011). However, some reports showed similar and/or lower cleavage rates compared to present study (Livingston et al., 2014). The efficiency of in vitro embryo development depends on oocyte donor, semen quality, and culture media and culture conditions employed during each phase of IVP (Brum et al., 2005). Beside these factors, the IVP efficiency is also affected by osmolality of media (Gordon, 1994), water quality used in different steps of IVP.

Table 2. Status of in vitro embryo production of buffalo ovary collected from slaughterhouse

\begin{tabular}{cccccc}
\hline Total COCs & $\begin{array}{c}\text { COCs with } \\
\text { for IVM }\end{array}$ & $\begin{array}{c}\text { cumulus } \\
\text { expansion (\%) }\end{array}$ & Cleavage (\%) & \multicolumn{3}{c}{ In vitro culture } \\
\cline { 4 - 6 } 358 & 285 & 202 & 137 & 65 & 0 \\
& $(79.61 \%)$ & $(56.42 \%)$ & $(38.27 \%)$ & $(18.15 \%)$ & Four cell (\%) \\
\hline
\end{tabular}

* Percentage was calculated on the basis of total no. of COCs placed for IVM

fertilization using fresh semen and they were cultured subsequently (IVC 1 and IVC 2 ) for 8 days. Following culture, 202 out of 358 COCs were undergone for cleavage step. Among the cleaved embryos, 65 were at 4-cell stage and 137 were at 2 -cell stage at the rate of $18.15 \%$ and $38.27 \%$ respectively. No embryo developed beyond 4-cell stage. Deb et al., (2016) found $74.16+5.49 \%$ maturation rate, $62.05+7.07 \%$ cleavage and $14.95=$ $4.39 \%$ blastocyst rate for slaughterhouse driven cattle oocytes. During IVM, 60.00 to $85.00 \%$ of the immature oocyte normally develops to metaphase II stage (Dey et al., 2011). Maturation rates of COCs found in the current study are within the range of normal standard culture system. Development rates to cleavage and blastocyst was lower in the

\section{Conclusion}

Comparatively higher numbers of ovaries were found without corpus luteum compared to ovaries with corpus luteum confirms that usually noncyclic buffaloes are slaughtered in the slaughterhouse and that is may be due to economic reason. Ovaries without CL contributing larger number of follicles aspirated per ovary compared to ovaries with CL. Furthermore, comparatively higher number of total COCs and superior quality of COCs were possible to obtain from without CL ovaries, suggested to be suitable for collecting COCs for initiating in vitro embryo production experiment in buffaloes. In vitro embryo production experiment concluded that current culture system support 
in vitro embryo production upto 4-cell stage. Improvement of culture condition may improve the efficiency of embryo production.

\section{Acknowledgement}

The authors thank Buffalo Development Project (Component B), for financial support to conduct this experiment.

\section{Reference}

Asad, L.Y. 2015. Effect of bovine serum albumin and follicular fluid on in vitro maturation, fertilization and development of goat embryos. Ph.D Thesis.Department of Animal Breeding and Genetics, Bangladesh Agricultural University.

Brum, D.S., Leivas F.G., Silva C.A.M., Rubin M.I.B., Rauber L.P., Fialho S.S. 2005. The developmental stages effects of number of oocytes and the volume of maturation medium in bovine in vitro embryo production. Animal Reproduction. 2: 70--73.

Dey, S.R., Deb, G.K., Ha, A.N., Lee J.I, Bang, J.I., Lee, K.L and Kong, I.K. 2011. Coculturing denuded oocytes during the in vitro maturation of bovine cumulus oocyte complexes exerts a synergistic effect on embryo development. Theriogenology.7:1064-77.

DLS. 2015. Annual report on livestock. Division of Livestock Statistics, Ministry of Fisheries and Livestock, Farmgate, Dhaka, Bangladesh.

Faruque, M.O., Hasnath, M.A and Siddique, N.U. 1990. Present status of buffaloes and their productivity. Asian-australasian Journal of Animal Science. 3: 287-292.
Ginther, O.J, Bergfelt, D.R, Kulick, L.J and Kot, K. 1996. Selection of the dominant follicle in cattle: role of two-way functional coupling between folliclestimulating hormone and the follicles. Biology of Reproduction. 62: 920927.

Gordon, I. 1994. Laboratory Production of Cattle Embryo. CAB International, Wallingford, Oxon OX 108 DE, UK.

Hafez, E.S.E. 1993. Reproduction in Farm Animals.Fifth Edition. Lea and Febriger: Philadelphia

Khandoker, M.A.M.Y., Jahan, N., Asad, L., Hoque, S.A.M.; Ahmed, S and Faruque, M.O. 2011. Qualitative and quantitative analysis of buffalo ovaries, follicles and oocytes in view of in vitro production of embryos. Bangladesh Journal of animal science, 40 (1\& 2): 23-27.

Khandoker, M.A.M.Y., Reza, M.M.T., Asad, L.Y., Saha, S., Apu, A.S. and Hoque, S.A.M. 2012. In vitro maturation of buffalo oocytes and fertilization by cattle spermatozoa. Bangladesh Journal of animal science 41 (1): 6-12.

Kumar, N, Paramasivan, S., Sood, P. and Singh, M. 2004. Micrometry of different category oocytes recovered from goat ovaries. Indian Journal of Animal Science. 74: 259-260

Nandi, S., Raghu, H.M., Ravindranatha, B.M. and Chauhan, M.S. 2002. Production of buffalo (Bubalus bubalis) embryos in vitro: premises and promises. Reproduction in Domestic Animals. 37: 65-74.

Webb, R., Campbell, B.K., Garveric, H.A. and Gong, J.G. 1999. Molecular mechanisms regulating follicular recruitment and selection. Journal of Reproduction and Fertility.45:123-126. 